\title{
Study on the Effect of Carbon Fiber Addition on the Properties of Rice Straw-Plastic Composites
}

\begin{abstract}
Xuesong Guan, ${ }^{\mathrm{a}, *}$ Dingguo Zhou, ${ }^{\mathrm{b}}$ Mingzhu Pan, ${ }^{\mathrm{b}}$ He Chen, ${ }^{\mathrm{b}}$ and Chunxiang Ding ${ }^{\mathrm{b}}$
Short carbon fiber (SCF), rice straw powder, and high-density polyethylene (HDPE) were melted, mixed, and compounded into composites by compression molding. The effects of carbon fiber content on the mechanical properties of rice straw-high density polyethylene composites (RHCs) were studied. The carbon fibers were characterized by a universal capability test machine (UCTM), scanning electron microscope (SEM), DMA dynamic mechanical analyzer, and a Fourier infrared spectrometer. The results showed that the addition of carbon fiber was beneficial to reduce the creep of RHCs. Meanwhile, the carbon fibers were broken after strength testing. The functional group types of rice straw WPC composites did not change, and the skeleton structure of WPC materials was still retained. When the content of carbon fibers was $9 \%$, a large number of carbon fibers were surrounded by the HDPE matrix; the fibers were broken and rarely pulled out. The results showed that good interfacial bonding took place between the carbon fibers and the composites. The maximum tensile strength of the RHC/S9 was 15.15 $\mathrm{MPa}$, which was $20.7 \%$ higher than that of default $\mathrm{RHC}$, and the modulus of elasticity was $52.5 \%$ higher than that of default RHC. However, due to the large content of carbon fiber, the distribution of the carbon fibers was uneven in the matrix, and the toughness was reduced.
\end{abstract}

Keywords: Rice straw; Wood plastic composites; Carbon fiber; Elastic properties

Contact information: a: College of Art and Design, Nanjing Forestry University, Nanjing 210037, China; b: College of Materials Science and Engineering, Nanjing Forestry University, Nanjing 210037, China;

* Corresponding author: $1173677982 @ q q . c o m$

\section{INTRODUCTION}

Wood-plastic composite (WPC) is a new kind of composite material with the advantages of corrosion resistance, dimensional stability, high strength, and so on (Dang et al. 2017). It is made by crushing waste wood and crop straw, mixing them with thermoplastics (PE, PP, PVC, PS, etc.), adding various additives, and then hot-pressing, compounding, or melt extrusion (Jumadi et al. 2018; Zhang et al. 2018). WPC has the characteristics of both plastics and wood fibers, and their comprehensive properties are excellent. They are widely used in construction, packaging, automobile, decoration, gardening, etc. (Albano et al. 2001; Markarian 2005; Panthapulakkal and Sain 2006; Liu et al. 2009).

Simply improving the mechanical strength of straw-plastic composites by interfacial modification cannot meet the demand for these composites, and some modifiers come with high cost. Improving the mechanical properties of straw-plastic composites with reinforcing fibers is proposed to be a good way to expand their applications. Many studies have shown that reinforcing fibers can effectively improve the mechanical properties of straw-plastic composites. Ting et al. (2010) used the melt mixing and molding method to 
make polypropylene-based wood plastic composites, which was also composited with sisal fiber (SF) and glass fiber (GF). The impact strength, flexural strength, and flexural modulus of the composites were improved to varying degrees. Jarukumjorn et al. (2008) reinforced sisal fiber/polypropylene composites with fiberglass. The results showed that the addition of glass fiber improves the tensile strength, flexural strength, impact resistance, heat resistance, and water resistance of the composites. Guan et al. (2011) showed that basalt fibers significantly improve the flexural strength, impact strength, and tensile strength of wood fibers/polymers. Cui et al. (2006) used L-shaped glass fiber (GF) with a larger length and diameter to reinforce WPC. The flexural strength, flexural modulus, and impact strength of the composites were improved compared with composites made of ordinary WPC.

Carbon fibers are lightweight, good-sized, high in tensile strength, and have the characteristics of common carbon materials, such as high temperature resistance, friction resistance, electrical conductivity, thermal conductivity, and small expansion coefficient (Chen et al. 2018; Dang et al. 2018). Carbon fiber composites are commonly prepared by mixing carbon fiber with resin, metal, ceramic, or another matrix composite. These resulting composites maintain some excellent properties of carbon fibers and have a wide utilization in modern industry (Li et al. 2005). Among these carbon fibers reinforced composites, thermoplastics or thermosetting resins are mostly applied as the matrix to obtain high-performance carbon fiber reinforced composites due to the good interfacial compatibility (Quan et al. 2020; Huang et al. 2020). To expand the utilization of carbon fiber in sustainable materials, many researchers have focused on the carbon fiber reinforced wood-based composites. Dang et al. (2018) pointed out that the incorporation of carbon fiber would obviously increase the modulus of rupture and modulus of elasticity of polyethylene/wood fiber composites, with an increase of $38 \%$ and $96 \%$, respectively. Zhang et al. (2019) prepared wood-flour/HDPE composites with continuous carbon fiber and found that carbon fiber made a large contribution to the increase in mechanical strength and toughness in comparison with glass fiber. Auriga et al. (2020) applied carbon fibers as a reinforcement layer between wood veneers and melamine-urea-formaldehyde resin. The cutting force showed better results for composite panels with carbon fiber in a perpendicular orientation. However, few studies on carbon fiber reinforced straw-plastic composites have been reported (Li et al. 2005; Ayrilmis and Kaymakci 2013; Du et al. 2015; Hao et al. 2018)

High density polyethylene (HDPE), as a thermoplastic material, has unique properties, such as excellent mechanical properties, good melt rheology, and it is commonly used plastic matrix in WPCs (Sun et al. 2019). Herein, HDPE was utilized to prepare the rice straw-high density polyethylene composites (RHCs), and the effects of carbon fiber content on the mechanical properties of resulting RHCs were investigated.

\section{EXPERIMENTAL}

\section{Materials}

Rice straw was taken from Suqian, Jiangsu Province, China, with a moisture content of $8.1 \%$. The rice straw powder was obtained by grinding the rice straw in a micro plant mill and screening it to pass 40 mesh and be retained on 80 mesh screens. The rice straw powder was dried to a moisture content of $2.0 \%$ at $103{ }^{\circ} \mathrm{C}$ and stored in a dryer. High density polyethylene (HDPE) was provided by Sinopec Yangzi Petrochemical Co., Ltd. 
(Nanjing Jiangsu Province China). The product model was HDPE 5000S, with a density $0.95 \mathrm{~g} / \mathrm{cm}^{3}$, and a melting index (MFI) $0.062 \mathrm{~g} / \mathrm{min}$ to $0.13 \mathrm{~g} / \mathrm{min}\left(190{ }^{\circ} \mathrm{C}\right)$. Its appearance was white and granular. It was crushed to pass through a $150 \mu \mathrm{m}$ screen and dried to about $2 \%$ moisture content at $103{ }^{\circ} \mathrm{C}$ and stored in a dryer. Carbon fiber with a length of $3 \mathrm{~mm}$ was supplied by Ze Yu Sen carbon fiber products Co., Ltd. (Nanjing Jiangsu Province, China).

Table 1. Distribution Ratio of Carbon Fiber/Rice Straw-Plastic Composites

\begin{tabular}{|c|c|c|c|c|c|c|c|}
\hline $\begin{array}{c}\text { Sample } \\
\text { Code }\end{array}$ & $\begin{array}{c}\text { HDPE } \\
(\%)\end{array}$ & $\begin{array}{c}\text { Rice Straw } \\
(\%)\end{array}$ & $\begin{array}{c}\text { SCF } \\
(\%)\end{array}$ & $\begin{array}{c}\text { Total Mass } \\
(\mathrm{g})\end{array}$ & $\begin{array}{c}\text { HDPE } \\
(\mathrm{g})\end{array}$ & $\begin{array}{c}\text { Rice Straw } \\
(\mathrm{g})\end{array}$ & $\begin{array}{c}\text { SCF } \\
(\mathrm{g})\end{array}$ \\
\hline $\mathrm{RHC}$ & 70 & 30 & 0 & 220 & 154 & 66 & 0 \\
\hline $\mathrm{RHC} / \mathrm{S} 3$ & 67 & 30 & 3 & 220 & 147.4 & 66 & 6.6 \\
\hline $\mathrm{RHC} / \mathrm{S} 6$ & 64 & 30 & 6 & 220 & 140.8 & 66 & 13.2 \\
\hline $\mathrm{RHC} / \mathrm{S} 9$ & 61 & 30 & 9 & 220 & 134.2 & 66 & 19.8 \\
\hline RHC/S12 & 58 & 30 & 12 & 220 & 127.6 & 66 & 26.4 \\
\hline
\end{tabular}

\section{Methods}

Preparation of carbon fiber/rice straw-plastic composites

A certain amount of carbon fibers was weighed and added into HDPE powder. The mixture of rice straw powder and HDPE/carbon fibers was pre-mixed evenly in the tray and then placed on a precision mill (Dongguan Zhenggong Mechanical and Electrical Equipment Technology Co., Ltd., ZG-160, Dongguan City, Guangdong Province, China). The blending time was $8 \mathrm{~min}$. After mixing, the mixture was moulded. The conditions of the pressing process were as follows: temperature, $175^{\circ} \mathrm{C}$; pressure, 50 bar; and process time, $3 \mathrm{~min}$. The sample needed for the flame retardant performance test was prepared in this way (Hao et al. 2018). The proportioning of carbon fiber/ rice straw-plastic composites is shown in Table 1.

\section{Mechanical properties of carbon fiber/rice straw-plastic composites}

Using the conditions set by GB/T13022 (1991), the test to determine tensile strength, was carried out on a computer-controlled electromechanical testing machine (Shenzhen New Sansi Material Testing Company, Shenzen, China). The dimensions of the sample were $100 \mathrm{~mm}$ (long) $\times 10 \mathrm{~mm}$ (wide) $\times 4 \mathrm{~mm}$ (thick); the loading speed was 1 $\mathrm{mm} / \mathrm{min}$. Continuous loading took place until the failure of the sample; this was repeated six times, and the average value was taken. Using the conditions set by GB/T9341 (2008), impact performance was tested on a pointer-type plastic pendulum impact testing machine (ZBC1251-1, Shenzhen New Sansi Material Testing Company, Shenzen, China). The dimensions of the sample were $80 \mathrm{~mm}$ (long) $\times 10 \mathrm{~mm}$ (wide) $\times 4 \mathrm{~mm}$ (thick). Continuous loading to failure was repeated six times and the average value was taken. Bending performance was tested in a computer-controlled electromechanical testing machine (CMT-4204, Shenzhen Xinsansi Material Testing Company, Shenzen, China). The dimensions of the sample were $80 \mathrm{~mm}$ (long) $\times 10 \mathrm{~mm}$ (wide) $\times 4 \mathrm{~mm}$ (thick). Continuous loading to failure was repeat 6 times, and the average value was taken (GB/T1451 2005). 
Scanning electron microscopy test of carbon fiber/rice straw-plastic composites

Scanning electron microscopy (SEM, JSM-7600F, Japan Electronics Co., Ltd) was used to observe the surface morphology of rice straw-plastic composites modified by carbon fibers. Before the test, the samples were ground and sifted, and the powder of 200 $\mu \mathrm{m}$ to $450 \mu \mathrm{m}$ in size was vacuum dried and sprayed with gold. The sample was observed under the acceleration voltage of $10 \mathrm{kV}$.

Creep (DMA) test of carbon fiber/rice straw-plastic composites

Creep resistance of carbon fiber/rice-straw wood-plastic composites was measured using a DMA dynamic mechanical analyzer (Q800, TA Instruments, USA) in a three-point bending mode. The test temperature was 0 to $1000{ }^{\circ} \mathrm{C}$, the test stress was $5 \mathrm{MPa}$, and the test time was $30 \mathrm{~min}$. Sample size: $60 \mathrm{~mm}$ (length) $\times 10 \mathrm{~mm}$ (width) $\times 4 \mathrm{~mm}$ (thickness).

\section{FTIR test of carbon fiber/rice straw-plastic composites}

An FTIR spectrometer (VERTEX 80V, Burker, Germany) was used to evaluate the functional groups of carbon fiber/rice straw-plastic composites. The surface of the composite was analyzed by attenuation total reflection infrared spectroscopy (FTIR), with a determination range of 4000 to $400 \mathrm{~cm}^{-1}$ and a resolution of $4 \mathrm{~cm}^{-1}$.

\section{RESULTS AND DISCUSSION}

\section{Mechanical Properties of Carbon Fiber/Rice Straw-Plastic Composites}

The mechanical performance of rice straw-plastic composites with and without carbon fiber reinforcement are exhibited in Fig. 1 and Table 2. With the incorporation of rice straw powder, both the tensile strength, impact strength, and bending strength of RHC had an obvious decrease, compared with those of HDPE by itself. Interestingly, the addition of carbon fibers showed a positive effect on both the bending strength and the tensile strength of the resulting composites. When the carbon fiber content was $9 \%$, the flexural strength of the composites increased by $26.5 \%$ compared with the default RHC. The flexural modulus increased by $7.7 \%$, but not significantly.

Rice straw powder, as the reinforcing filler, strengthened the elastic modulus of HDPE, as shown in Fig. 1. Meanwhile, the elastic modulus increased gradually with the increase of carbon fiber mass fraction from $3 \%$ to $9 \%$. When the content of carbon fiber was $9 \%$, the elastic modulus increased by $52.5 \%$ compared with default RHC. The results showed that the elasticity and deformation resistance of carbon fiber/rice straw-plastic composites increased with the increase of carbon fiber.

Impact strength can characterize the toughness of the material. When the carbon fiber content was 3\%, the impact strength of RHC/S3 composite was $32 \%$ higher than that of default RHC. This showed that the addition of carbon fiber improved the brittleness of RHCs. When the amount of carbon fiber was too high, agglomeration was more likely to occur in the extrusion process, and the dispersion uniformity decreased. When subjected to external impacts, the agglomerated parts that lacked resin penetration were prone to fracture, so when the carbon fiber content was 9\%, the toughening effect was not significantly improved (Du et al. 2015). Although rice straw is not as strong as wood fiber, comparing with the impact strength of other wood-plastic composites (Vedrtnam et al. 2019), carbon fiber/rice straw-plastic composites became even tougher, which might be due to the good compatibility between carbon fiber and polymer matrix. 

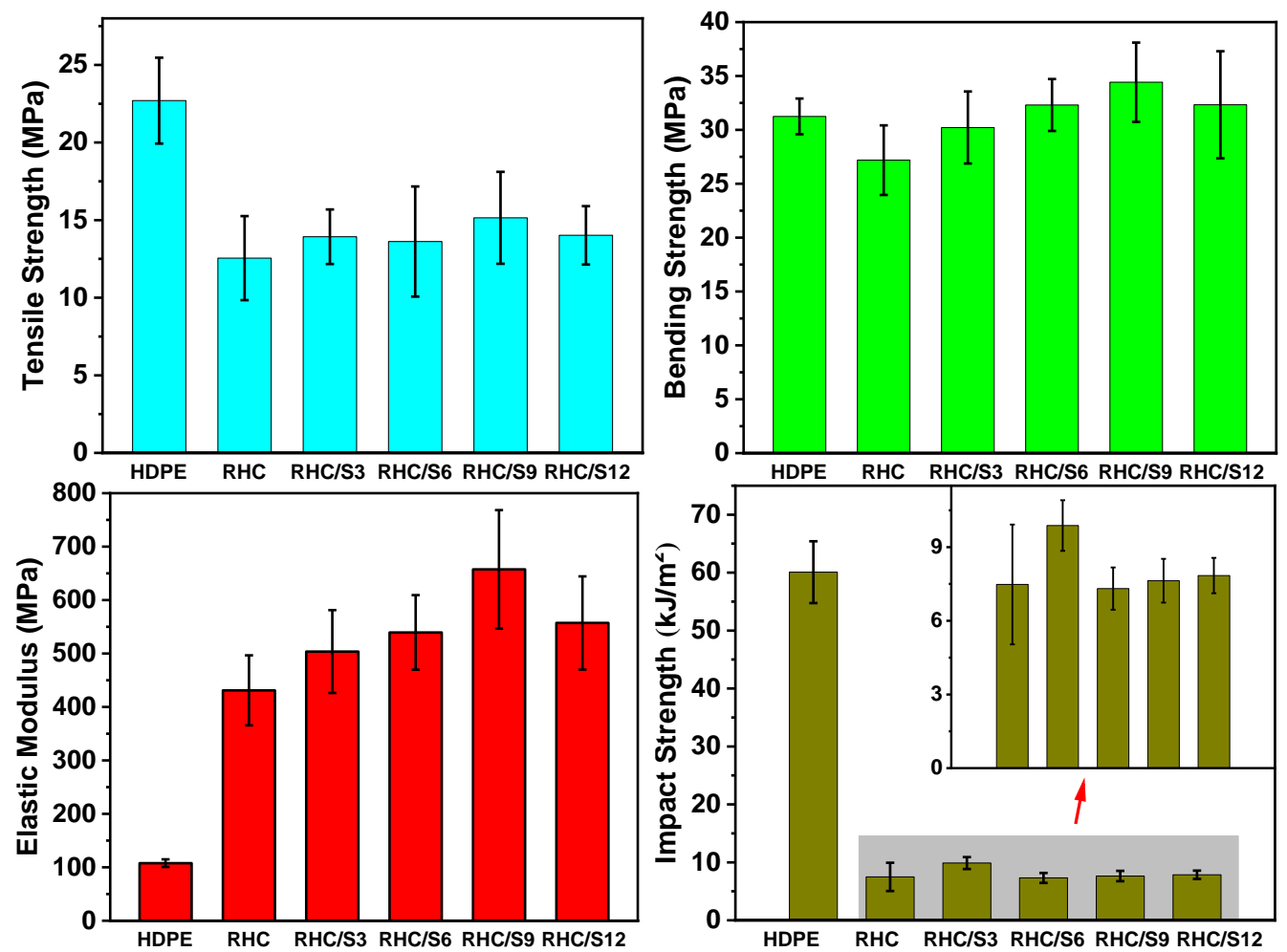

Fig. 1. Mechanical properties of carbon fiber/rice straw-plastic composites

Table 2. Mechanical Properties of Carbon Fiber/Rice Straw-Plastic Composites

\begin{tabular}{|c|c|c|c|c|c|c|}
\hline Sample & $\begin{array}{c}\text { Tensile } \\
\text { Strength } \\
(\mathrm{MPa})\end{array}$ & $\begin{array}{c}\text { Impact } \\
\text { Strength } \\
(\mathrm{MPa})\end{array}$ & $\begin{array}{c}\text { Bending } \\
\text { Strength } \\
(\mathrm{MPa})\end{array}$ & $\begin{array}{c}\text { Flexural } \\
\text { Modulus } \\
(\mathrm{MPa})\end{array}$ & $\begin{array}{c}\text { Modulus of } \\
\text { Elasticity } \\
(\mathrm{MPa})\end{array}$ & $\begin{array}{c}\text { Elongation } \\
\text { at Break } \\
(\%)\end{array}$ \\
\hline \multirow{2}{*}{$\mathrm{HDPE}$} & 22.7 & 60.08 & 31.25 & 783.90 & 107.80 & 19.06 \\
& $(2.77)$ & $(5.34)$ & $(1.66)$ & $(157.39)$ & $(7.02)$ & $(2.56)$ \\
\hline \multirow{2}{*}{$\mathrm{RHC}$} & 12.55 & 7.48 & 27.19 & 1603.97 & 431.10 & 3.91 \\
& $(2.71)$ & $(2.44)$ & $(3.23)$ & $(132.52)$ & $(65.58)$ & $(1.59)$ \\
\hline \multirow{2}{*}{$\mathrm{RHC/S3}$} & 13.93 & 9.88 & 30.22 & 1256.34 & 503.69 & 3.06 \\
& $(1.76)$ & $(1.03)$ & $(3.34)$ & $(174.24)$ & $(77.47)$ & $(1.34)$ \\
\hline \multirow{2}{*}{$\mathrm{RHC} / \mathrm{S} 6$} & 13.62 & 7.31 & 32.31 & 1543.75 & 539.45 & 3.22 \\
& $(3.55)$ & $(0.86)$ & $(2.41)$ & $(103.52)$ & $(69.82)$ & $(0.62)$ \\
\hline \multirow{2}{*}{$\mathrm{RHC} / \mathrm{S} 9$} & 15.15 & 7.63 & 34.42 & 1415.96 & 657.39 & 2.64 \\
& $(2.96)$ & $(0.89)$ & $(3.68)$ & $(185.78)$ & $(110.86)$ & $(0.36)$ \\
\hline \multirow{2}{*}{$\mathrm{RHC/S12}$} & 14.02 & 7.84 & 32.33 & 1727.88 & 557.14 & 2.58 \\
& $(1.88)$ & $(0.72)$ & $(4.97)$ & $(417.28)$ & $(87.29)$ & $(0.27)$ \\
\hline
\end{tabular}

\section{Scanning Electron Microscopy (SEM) Analysis}

The interfacial bonding of the RHC with contents of $3 \%$ and $9 \%$ short carbon fibers under scanning electron microscopy is shown in Fig. 2. Rice straw and HDPE were the main load-bearing parts in the composite materials, which were closely combined and evenly distributed. When the content of carbon fibers was 3\%, the rod-like carbon fibers were sparsely distributed in the composites, with smooth surfaces and low roughness. When the content of carbon fibers was 9\%, a large number of carbon fibers were surrounded by HDPE matrix, and the fibers are broken, rarely pulled out. This showed that the carbon fibers and composites formed a good interface bonding, which exerted the 
advantages of a high tensile strength in the carbon fibers and enhanced the tensile strength of the composites. At the same time, a large number of carbon fibers were dispersed unevenly in the matrix, which resulted in no obvious toughening effect of the composites (Lu et al. 2013; You and Li 2013; Li et al. 2014).
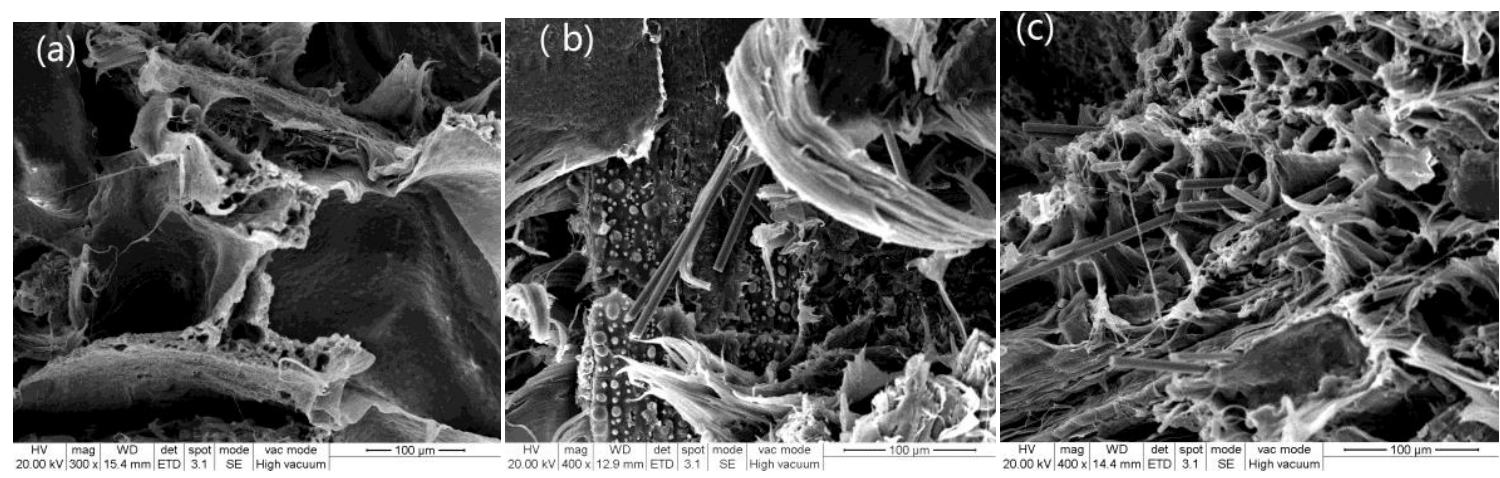

Fig. 2. Micrographs of tensile section of rice straw-plastic composites with different carbon fiber content: (a) RHC, (b) RHC/S3, (c) RHC/S9

\section{Effect of SCF on Creep Properties of Rice Straw-Plastic Composites}

Figure 3 shows the effect of different carbon fiber dosages on the creep properties of the RHCs. The creep rate of the RHCs decreased gradually with the extension of time, and the strain increased gradually and before stabilizing. The addition of SCF was beneficial to reduce the deformation of the rice straw wood plastic composites. When SCF was not added, the creep of RHC was $0.16 \%$. When SCF was added, the creep properties of rice straw WPC decreased in varying degrees. When $6 \%$ SCF was added, the creep properties of the RHCs reached the lowest value of $0.12 \%$, which was $25 \%$ lower than that of the pure rice straw wood-plastic composites.

The main reason was that the HDPE matrix had good toughness, poor stiffness, high flexibility of molecular segments, easy movement, and weak interfacial bonding force. SCF filling can inhibit the movement of the molecular chains of HDPE, strengthening the rigidity of RHCs, reducing creep, and improving the creep properties of RHCs (Wang et al. 2007; Du et al. 2015; Zhao 2016; Feng and Zhao 2018).
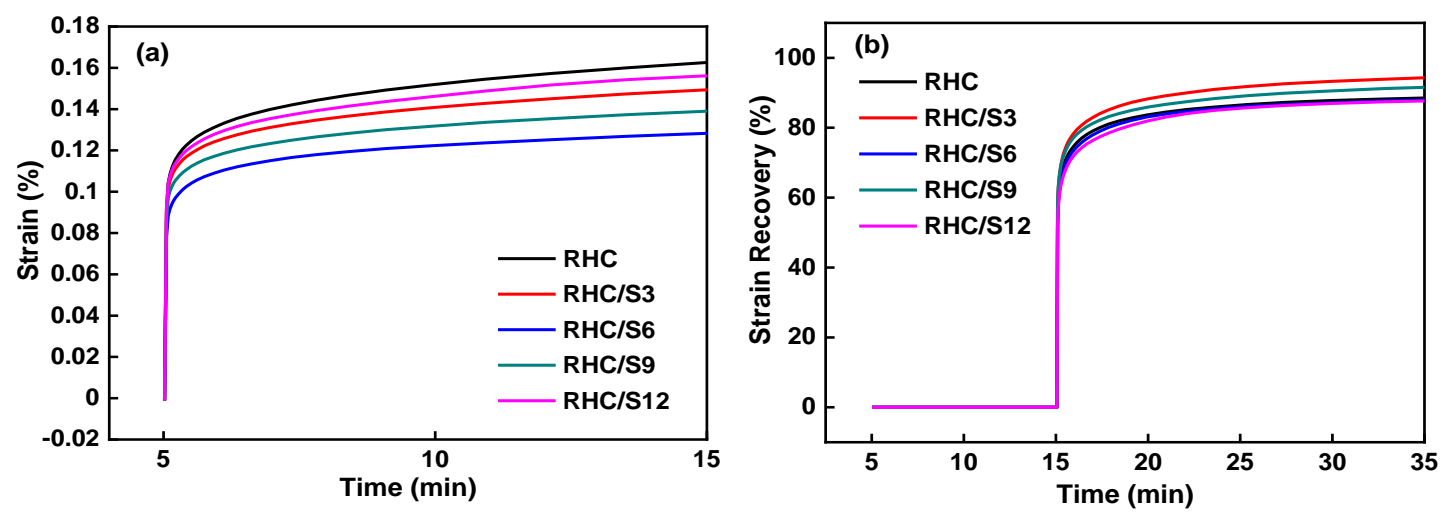

Fig. 3. Effect of different carbon fiber dosage on creep properties of rice straw-plastic composites 


\section{FTIR Analysis of Carbon Fiber/Rice Straw-Plastic Composites}

Figure 4 shows the FTIR spectrum of rice straw-plastic composites before and after the addition of carbon fiber. The absorption peaks and their attribution results are shown in Table 3. The peak at $730 \mathrm{~cm}^{-1}$ was attributed to the vibration of $-\left(\mathrm{CH}_{2}\right)_{\mathrm{n}^{-}}(\mathrm{n} \geqslant 4)$ of polyethylene; The peak at $1030 \mathrm{~cm}^{-1}$ was attributed to the stretching vibration of cellulose alkoxy group C-O-R. The peak around $1500 \mathrm{~cm}^{-1}$ was attributed to the bending vibration of - $\mathrm{CH}_{2}$ - in polyethylene. At $2850 \mathrm{~cm}^{-1}$ was the symmetric stretching vibration of $-\mathrm{CH}_{2}$ - in polyethylene. At $2900 \mathrm{~cm}^{-1}$ was the asymmetric stretching vibration peak of $-\mathrm{CH}_{2}$ - in polyethylene. The types of functional groups did not change when carbon fibers were added. The results showed that the skeleton structure of RHC remained after carbon fiber was added.

Table 3. Location and Attribution of Each Absorption Peak in FTIR Spectrum of Rice Straw - Plastic Composites

\begin{tabular}{|c|c|}
\hline Wavenumber $/ \mathrm{cm}^{-1}$ & The ownership of the peak \\
\hline 2900 & $-\mathrm{CH}_{2}-$ Asymmetric stretching vibration peak \\
\hline 2850 & $-\mathrm{CH}_{2}-$ Symmetric stretching vibration peak \\
\hline 1500 & $-\mathrm{CH}_{2}$ - Bending vibration peak \\
\hline 1030 & $\mathrm{C}-\mathrm{O}-\mathrm{R}$ Stretching vibration \\
\hline 730 & $-\left(\mathrm{CH}_{2}\right) \mathrm{n}^{-}(\mathrm{n} \geq 4)$ In-plane oscillatory peaks \\
\hline
\end{tabular}

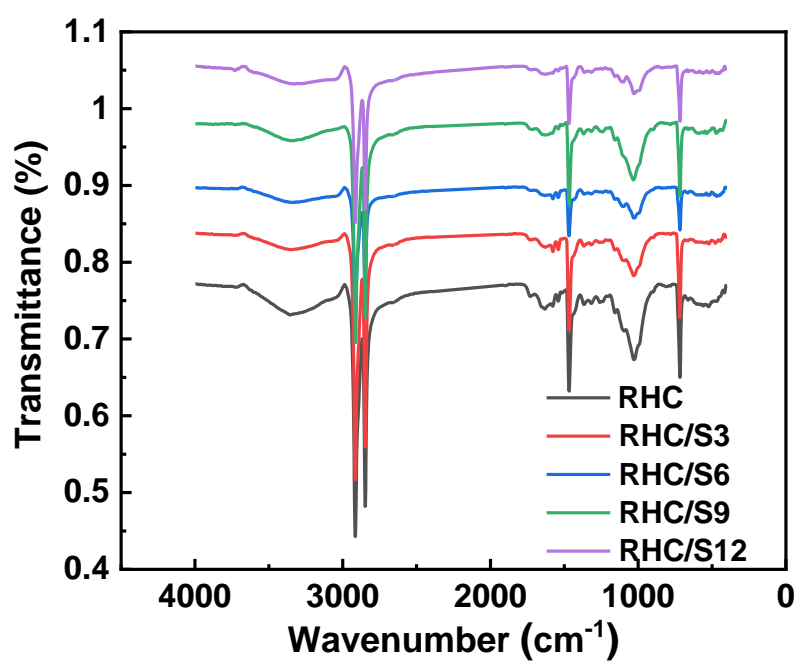

Fig. 4. FTIR spectra of rice straw-plastic composites with different carbon fiber dosages

\section{CONCLUSIONS}

Short-cut carbon fiber with different contents was fused and blended with rice straw-plastic composite. The short-cut carbon fiber reinforced rice straw-plastic composite was prepared by the method of molding. The following conclusions were obtained:

1. Scanning electron micrographs showed that the addition of $3 \%$ carbon fibers resulted in the rod-like carbon fibers to be sparsely distributed in the composites with smooth 
surface and low roughness. When $9 \%$ carbon fibers were added, a large number of carbon fibers were surrounded by the high-density polyethylene (HDPE) matrix, and fibers were broken in the course of tensile strength tests, such that they rarely were pulled out. This showed that carbon fiber and composite materials formed good interfacial bonding, so that the tensile strength of the composites was enhanced. At the same time, it was observed that a large number of carbon fibers were dispersed unevenly in the matrix, which resulted in no obvious toughening effect of the composites.

2. When carbon fibers were not added, the creep of RHC was $0.16 \%$. When carbon fibers were added, the creep properties of RHC decreased in varying degrees. When $6 \%$ carbon fiber was added, the creep property of RHC/S6 reached the lowest value of $0.12 \%$. Compared with pure rice straw-plastic composite, the creep property of rice straw-plastic composite decreased by $25 \%$. The addition of carbon fiber can reduce the deformation of rice straw-plastic composite (Park and Balatinecz 1998; LabVIEW User Manual 2000; Lee and Kim 2008; Yang et al. 2007; Najafi and Kordkheili 2011; Tang et al. 2011).

3. The tensile strength of default RHC was $12.55 \mathrm{MPa}$. When $9 \%$ SCF was added, the tensile strength of RHC/S9 reached the maximum value of $15.15 \mathrm{MPa}$, which was $20.7 \%$ higher than that of default RHC, respectively. The flexural strength also showed the same trend as the tensile strength. When the content of carbon fibers was $9 \%$, the flexural strength of the composites increases by $26.5 \%$ compared with that of default RHC. The flexural modulus increased by $7.7 \%$, but not significantly. When the content of carbon fiber was 3\%, the impact strength of RHC/S3 composite was 32\% higher than that of default RHC. When the content of carbon fiber was too high, the distribution of carbon fiber in matrix was uneven and the toughness was not obviously improved.

\section{ACKNOWLEDGMENTS}

The authors are grateful for the support of the U.S. Department of Biomaterials Research, Grant No. 2005-1234.

\section{REFERENCES CITED}

Albano, C., Ichazo, M., González, J., Delgado, M., and Poleo, R. (2001). "Effects of filler treatments on the mechanical and morphological behavior of PP+wood flour and PP+sisal fiber," Materials Research Innovations 4(5-6), 284-293. DOI: 10.1007/s100190000108

Auriga, A., Gumowska, A. Szymanowski, K., Wronka, A., Robles, E., Ocipka, P., and Kowaluk, G. (2020). "Performance properties of plywood composites reinforced with carbon fibers," Composite Structures 248, 112533. DOI:

10.1016/j.compstruct.2020.112533

Ayrilmis, N., and Kaymakci, A. (2013). "Fast growing biomass as reinforcing filler in thermoplastic composites: Paulownia elongate wood," Industrial Crops and Products 43, 457-464. DOI: 10.1016/j.indcrop.2012.07.050 
Chen, Y. P., Sheng, C. M., Dang, B. K., Qian, T. M., Jin, C. D., and Sun, Q. F. (2018). "High mechanical property of laminated electromechanical sensors by carbonized nanolignocellulose/graphene composites," ACS Applied Materials and Interfaces 10, 7344-7351. DOI: 10.1021/acsami.7b19353

Cui, Y., Noruziaan, B., Lee, S., Cheung, M., and Tao, J. (2006). "Glass fiber/woodplastic hybrid composites and their synergistic enhancement effects," Polymer Materials Science and Engineering 22(3), 231-234.

Dang, B. K., Chen, Y. P., Shen, X. P., Chen, B., Sun, Q. F., and Jin, C. D. (2017). "Fabrication of a nano-Zno/polyethylene/wood-fiber composite with enhanced microwave absorption and photocatalytic activity via a facile hot-press method," Materials 10, 1267. DOI:10.3390/ma10111267

Dang, B. K., X. P., Chen, Yang, N., Chen, B., and Sun, Q. F. (2018). "Effect of carbon fiber addition on the electromagnetic shielding properties of carbon fiber/ polyacrylamide/wood-based fiberboards," Nanotechnology 29, 195605. DOI: 10.1088/1361-6528/aab243

Du, H. H., Wang, W. H., Wang, H. G., and Wang, Q. W. (2015). "Effect of wood fiber content on the grinding characteristics of wood-plastic composites," Journal of Building Materials 18(2), 333-339. • .

Du, F., and Wang, W. (2015). "Preparation and mechanical properties of carbon fiber reinforced wood powder/polyethylene composites," Journal of Nanjing Forestry University (Natural Science) 39(2), 132-136.

Feng, L., and Zhao, C. (2018). "Polyvinyl wood plastic composite," China Plastic Creep Variable Factors Analysis 4, 41-44. •

GB/T13022 (1991). "Plastics - Determination of tensile properties of films," Standardization Administration of China, China.

GB/T1451- 2005 (2005). "Fiber-reinforced plastics composites - Determination of charpy impact properties," Standardization Administration of China, China.

GB/T 9341-2008 (2008). "Plastics - Determination of flexural properties," Standardization Administration of China, China.

Guan, S., Wan, W., Wang, L., Xu. Y., and Chen, J. (2011). "Mechanical properties of basalt fiber reinforced wood-plastic composites," Acta Materiae Compositae Sinica/Journal of Composite Materials 28(5), 162-167.

Hao, J., Feng, D., and Wang, W. (2018). "Effect of surface treatment of chopped carbon fiber on properties of wood flour/high density polyethylene composites," Journal of Composite Materials 35(2), 298-303.

Huang, M. M., Li, W. W., Liu, X. J., Feng, M., and Yang J. (2020). "The effects of cauliflower-like short carbon fibers on the mechanical properties of rigid polyurethane matrix composites," Polymer Testing 89, 106718. DOI: 10.1016/j.polymertesting.2020.106718

Jarukumjorn, K., Suppakarn, N., and Kluengsamrong, J. (2008). "Mechanical and morphological properties of sisal/glass fiber-polypropylene composites," Advanced Materials Research 47-50, 486-489. DOI: 10.4028/www.scientific.net/AMR.4750.486

Jumadi, M. T., Mansor, M. R., and Mustafa, Z. (2018). "Characterisation of wood plastic composite manufactured from kenaf fibre reinforced recycled-unused plastic blend," Composites Structure 189, 510-515. DOI: 10.1016/j.compstruct.2018.01.090

Lee, H. K., and Kim, D. S. (2008). "Preparation and physical properties of 
wood/polypropylene/clay nanocomposites," Journal of Applied Polymer Science 111(6), 2769-2776. DOI: 10.1002/app.29331

Li, S., and Li, D. (2014). "Carbon fiber reinforced highly filled charcoal powder/ultra high molecular weight polyethylene composites," Materials Letters 134, 99-102. DOI: $10.1016 /$ j.matlet.2014.07.081

Li, X., Zhang, X., and Wang, H. (2005). "Development of carbon fiber and its application status," High-Tech Fiber and Application 30(5), 24-30.

Liu, H., Wu, Q., and Zhang, Q. (2009). "Preparation and properties of banana fiberreinforced composites based on high density polyethylene (HDPE)/Nylon-6 blends," Bioresource Technology 100(23), 6088-6097. DOI: 10.1016/j.biortech.2009.05.076

Liu, T., Lu, S., Wang, Y.-1., Yu, C. H., and Luo, C. X. (2010). "Structure and properties of sisal and glass fibers hybrid reinforced polypropylene," Plastics 3, 63-65.

Lu, T., Jiang, M., Jiang, Z., Hui, D., Wang, Z., and Zhou, Z. (2013). "Effect of surface modification of bamboo cellulose fibers on mechanical properties of cellulose/epoxy composites," Composites Part B: Engineering 51, 28-34. DOI:

10.1016/j.compositesb.2013.02.031

Markarian, J. (2005). "Wood-plastic composites: current trends in materials and processing," Plastics, Additives and Compounding 7(5), 20-26. DOI: 10.1016/S1464391X(05)70453-0

Najafi, S. K., and Kordkheili, H. Y. (2011). "Effect of sea water on water absorption and flexural properties of wood-polypropylene composites," European Journal of Wood and Wood Products 69(4), 553-556. DOI: 10.1007/s00107-010-0518-7

National Instruments Corporation (2000). LabVIEW User Manual[Z], National Instruments, Austin, TX.

Panthapulakkal, S., and Sain, M. (2006). "Injection molded wheat straw and corn stem filled polypropylene composites," Journal of Polymers and the Environment 14(3), 265-272. DOI: 10.1007/s10924-006-0021-8

Park, B. D, and Balatinecz, J. J (1998). "Short term flexural creep behavior of woodfiber/polypropylene composites," Polymer Composites 19(4), 377-382. DOI: 10.1002/pc.10111

Quan, D., Alderliesten, R., Dransfeld, C., Murphy, N., Ivanković, A., and Benedictus, R. (2020). "Enhancing the fracture toughness of carbon fibre/epoxy composites by interleaving hybrid meltable/non-meltable thermoplastic veils," Composite Structures 112699. DOI: 10.1016/j.compstruct.2020.112699

Sun, Y. N., Guo, L. M., Liu, Y. N., Wang, W. H., and Song, Y. M. (2019). “Glue wood veneer to wood-fiber-high-density-polyethylene composite," International Journal of Adhesion and Adhesives 95, 102444. DOI: 10.1016/j.ijadhadh.2019.102444

Tang, L. C, Zhang, H., Wu, X.P., and Zang, Z. (2011). "A novel failure analysis of multiwalled carbon nanotubes in epoxy matrix," Polymer 52(9), 2070-2074. DOI: 10.1016/j.polymer.2011.03.002

Vedrtnam, A., Kumar S., and Chaturvedi, S. (2019). "Experimental study on mechanical behavior, biodegradability, and resistance to natural weathering and ultraviolet radiation of wood-plastic composites," Composites Part B: Engineering 176(1), 107282. DOI: 10.1016/j.compositesb.2019.107282

Wang, K., Zhao Y., and Zu, F. (2007). "Bending and creep properties of wood-plastic composites filled with montmorillonite," Polymer Materials Science and Engineering 23(6), 109-112.

Yang, J., Zhang, Z., Friedrich, K., and Schlarb, A. K. (2007). “Creep resistant polymer 
nanocomposites reinforced with multiwalled carbon nanotubes," Macromolecular Rapid Communications 28(8), 955-961. DOI: 10.1002/marc.200600866

You, Z., and Li, D. (2013). "The dynamical viscoelasticity and tensile property of new highly filled charcoal powder/ultra-high molecular weight polyethylene composites," Materials Letters 112, 197-199. DOI: 10.1016/j.matlet.2013.09.013

Zhang, J. F., Li, Y., Xing, D., Wang, Q. W., Wang, H. G., and Koubaa, A. (2019). "Reinforcement of continuous fibers for extruded wood-flour/HDPE composites: Effects of fiber type and amount," Construction and Building Materials 228(20), 116718. DOI: 10.1016/j.conbuildmat.2019.116718

Zhang, X. L., Hao, X. L., Hao, J. X., and Wang Q. W. (2018). "Heat transfer and mechanical properties of wood-plastic composites filled with flake graphite," Thermochimica Acta 664, 26-31. DOI: 10.1016/j.tca.2018.04.003

Zhao, C. (2016). Creep Performance Research and Test Device Design of PE Based Wood-Plastic Composite, Doctoral Dissertation, Northeast Forestry University, Harbin, China.

Article submitted: December 18, 2018; Peer review completed: April 8, 2019; Revised version received and accepted: July 29, 2020; Published: March 22, 2021.

DOI: 10.15376/biores.16.2.3411-3421 